\title{
Luteolin increases susceptibility to macrolides by inhibiting MsrA efflux pump in Trueperella pyogenes
}

\author{
Yuru Guo, Chengcheng Huang, Hongyu Su, Zehui Zhang, Menghan Chen, Ruxia Wang, Dexian Zhang, \\ Luyao Zhang and Mingchun Liu* (1)
}

\begin{abstract}
Trueperella pyogenes (T. pyogenes) is an opportunistic pathogen associated with a variety of diseases in many domestic animals. Therapeutic treatment options for T. pyogenes infections are becoming limited due to antimicrobial resistance, in which efflux pumps play an important role. This study aims to evaluate the inhibitory activity of luteolin, a natural flavonoid, on the MsrA efflux pump and investigate its mechanism. The results of antimicrobial susceptibility testing indicated that the susceptibility of $m s r A$-positive $T$. pyogenes isolates to six macrolides increased after luteolin treatment, while the susceptibility of $m s r A$-negative isolates showed no change after luteolin treatment. It is suspected that luteolin may increase the susceptibility of T. pyogenes isolates by inhibiting MsrA activity. After 1/2 MIC luteolin treatment for $36 \mathrm{~h}$, the transcription level of the MsrA gene and the expression level of the MsrA protein decreased by $55.0-97.7 \%$ and $36.5-71.5 \%$, respectively. The results of an affinity test showed that the equilibrium dissociation constant (KD) of luteolin and MsrA was $6.462 \times 10^{-5} \mathrm{M}$, and hydrogen bonding was predominant in the interaction of luteolin and MsrA. Luteolin may inhibit the ATPase activity of the MsrA protein, resulting in its lack of an energy source. The current study illustrates the effect of luteolin on MsrA in T. pyogenes isolates and provides insight into the development of luteolin as an innovative agent in combating infections caused by antimicrobial-resistant bacteria.
\end{abstract}

Keywords: Trueperella pyogenes, luteolin, efflux pump inhibitors, MsrA efflux pump

\section{Introduction}

Trueperella pyogenes (T. pyogenes), formerly classified as Corynebacterium pyogenes, is a gram-positive, non-spore-forming, nonencapsulated, nonmotile, pleomorphic, rod-shaped bacterium [1-3]. T. pyogenes is an opportunistic and zoonotic pathogen. In domestic and wildlife animals, it often causes various suppurative infections, including liver abscess, arthritis, pneumonia, metritis, and mastitis $[4,5]$. Infections caused by $T$.

*Correspondence: liumingchun@syau.edu.cn

Key Laboratory of Livestock Infectious Diseases in Northeast China, Ministry of Education, College of Animal Science and Veterinary Medicine, Shenyang Agricultural University, Shenyang, Liaoning, China pyogenes in humans are rare and usually occur with occupational exposure, especially in individuals in contact with animals and their environment. It has been reported that $T$. pyogenes causes endocarditis, pneumonia, arthritis, and various purulent lesions and abscesses in humans $[3,6]$.

Trueperella pyogenes is an important causative agent in cattle and pigs due to the fact that it causes substantial economic losses [1]. At present, the treatment of infections caused by $T$. pyogenes in veterinary clinics still relies on antibiotics [7-9]. However, the antimicrobial resistance of $T$. pyogenes is becoming severe because of the overuse of antimicrobial drugs in veterinary clinical treatment. Zhang reported that T. pyogenes isolated original author(s) and the source, provide a link to the Creative Commons licence, and indicate if changes were made. The images or other third party material in this article are included in the article's Creative Commons licence, unless indicated otherwise in a credit line to the material. If material is not included in the article's Creative Commons licence and your intended use is not permitted by statutory regulation or exceeds the permitted use, you will need to obtain permission directly from the copyright holder. To view a copy of this licence, visit http://creativecommons.org/licenses/by/4.0/. The Creative Commons Public Domain Dedication waiver (http://creativeco mmons.org/publicdomain/zero/1.0/) applies to the data made available in this article, unless otherwise stated in a credit line to the data. 
from dairy cows was highly resistant to tetracycline and doxycycline [10]. High $\mathrm{MIC}_{90}$ values for oxytetracycline $(32 \mu \mathrm{g} / \mathrm{mL})$, tylosin $(64 \mu \mathrm{g} / \mathrm{mL})$ and erythromycin $(1024 \mu \mathrm{g} / \mathrm{mL})$ have been observed among T. pyogenes isolates from ruminants [11]. Most $T$. pyogenes isolates from domestic animals and European bison were nonsusceptible to enrofloxacin and ciprofloxacin [7]. Antimicrobial resistance, especially multidrug resistance, seriously threatens the therapeutic efficiency of antimicrobial agents. To cope with excessive resistance in bacteria, it is urgent to develop new drugs to combat this resistance.

Bacteria can develop resistance to antibiotics through various mechanisms: (i) reducing the permeability of the cell membrane, (ii) pumping antibiotics out of the cells via efflux pump systems, (iii) expressing enzymes that can destroy or modify antibiotics, and (iv) modifying the specific target of antibiotics $[12,13]$. There are five major families of bacterial efflux pumps, among which ATPbinding cassette $(\mathrm{ABC})$ family transporters can be found in both gram-positive and gram-negative bacteria. The macrolide resistance gene $m s r A$, which encodes an efflux pump, is prevalent in Staphylococcus aureus, Staphylococcus epidermidis and other staphylococcal species. As a member of the $\mathrm{ABC}$ transporters, the MsrA pump confers resistance to 14- and 15-membered ring macrolides and streptogramin B [14].

Identifying effective efflux pump inhibitors (EPIs) that prevent bacteria from pumping antibiotics out of the cell contributes to improving the clinical performance of antibiotics [15]. Many EPIs have been identified, such as $\beta$-naphthylamide, carbonyl cyanide- $m$-chlorophenylhydrazone, verapamil, and reserpine [16]. However, most of these molecules are limited in clinical application due to their toxicity, instability and low bioavailability [17-20]. Recently, interest has been growing in the identification of EPIs from natural products, including flavonoids. It has been reported that baicalein could improve the susceptibility of Staphylococcus aureus to antibiotics by inhibiting NorA and TetK efflux pumps [21]. The flavonoids skullcapflavone II and nobiletin have been found to interfere with efflux pump activity in $M$. aurum and $M$. smegmatis [22].

However, studies carried out to evaluate the effect of natural products on the MsrA efflux pump are scarce. Luteolin, a typical flavonoid, has many pharmacological activities, such as antibacterial, anti-inflammatory, antioxidant, and antitumour activities [23, 24]. In addition, our previous study showed that luteolin could increase the susceptibility of multidrug-resistant $T$. pyogenes to aminoglycoside antibiotics by inhibiting the MATE efflux pump [25]. This study aims to explore the potential activity of luteolin as an MsrA inhibitor and its mechanism of action.

\section{Materials and methods}

\section{Strains and culture conditions}

Trueperella pyogenes isolates were obtained from cows suffering from endometritis and preserved in our laboratory. Isolates were classified as $m s r A$-positive or $m s r A$ negative strains by PCR amplification of the $m s r A$ gene in our previous study. Eight $m s r A$-positive $T$. pyogenes isolates (HC03-1, $\mathrm{HC}-\mathrm{H} 03-3, \mathrm{HC}-\mathrm{H} 02-2, \mathrm{BM}-07-1$, BM-H06-3, BM-H11-1, BM-H01-1 and RY04-2) and two $m s r A$-negative T. pyogenes isolates (HC-H10 and RY143) were included in this study. T. pyogenes isolates were grown on Mueller-Hinton agar (MH(A), AOBOX, Beijing, China) supplemented with $5 \%$ sterile defibrinated sheep blood (Solarbio, Beijing, China) for $48 \mathrm{~h}$ at $37^{\circ} \mathrm{C}$ in $5 \% \mathrm{CO}_{2}$. Before assays, $3-5$ colonies were inoculated into nutrient broth (NB, AOBOX, Beijing, China) containing $8 \%$ foetal bovine serum (FBS, Gibco, USA) and cultured in tubes for $24 \mathrm{~h}$ at $37{ }^{\circ} \mathrm{C}$ with shaking at $180 \mathrm{rpm}$ to obtain a bacterial suspension that reached the logarithmic phase.

\section{Antimicrobial agents and chemicals}

Macrolides, including erythromycin, roxithromycin, acetylspiramycin, tilmicosin, azithromycin and tylosin, were obtained from the China Institute of Veterinary Drug Control. Luteolin was purchased from Shanghai Pureone Biotechnology Co., Ltd. (Shanghai, China) and dissolved in $1 \%$ dimethyl sulfoxide (DMSO, Sigma-Aldrich, Shanghai, China) to produce a stock solution. Reserpine was purchased from Chengdu Must Bio-technology Co., Ltd. (Chengdu, China) and dissolved in 1\% DMSO to produce a stock solution. Reserpine was used as a test control due to its previously demonstrated action as an EPI [26].

\section{Antimicrobial susceptibility testing}

Minimum inhibitory concentrations (MICs) of luteolin and reserpine against $T$. pyogenes isolates were determined by the broth microdilution method according to Clinical and Laboratory Standards Institute (CLSI) guidelines, with the following modification [27]. Briefly, $100 \mu \mathrm{L}$ of serial twofold dilutions of luteolin and reserpine in Mueller-Hinton broth $\mathrm{MH}(\mathrm{B}), \mathrm{AOBOX}$, Beijing, China) containing 8\% FBS were dispensed in U-bottom 96-well microtitre plates (Corning, USA). An equal volume of adjusted inoculum $\left(5 \times 10^{5} \mathrm{CFU} / \mathrm{mL}\right)$ was added to each well of the microplate up to a final volume of 200 $\mu \mathrm{L}$. The microtitre plates were observed after $24 \mathrm{~h}$ incubation at $37{ }^{\circ} \mathrm{C}$ with $5 \% \mathrm{CO}_{2}$. The MICs were defined as the lowest concentrations of luteolin and reserpine that prevented visible bacterial growth.

The effects of luteolin on the susceptibility of $T$. pyogenes to six macrolides were subsequently investigated. Briefly, a T. pyogenes suspension cultured to the 
logarithmic phase was adjusted to a final concentration of $5 \times 10^{5} \mathrm{CFU} / \mathrm{mL}$ and mixed with different final concentrations of luteolin (1/2 MIC, 1/4 MIC, 1/8 MIC, and $1 / 16 \mathrm{MIC})$. The same final concentration of DMSO (v/v, $0.01 \%$ ) was added as a solvent control. The mixture was incubated in tubes at $37^{\circ} \mathrm{C}$ and $180 \mathrm{rpm}$ for $18,24,30$, $36,42,48,54$, and $60 \mathrm{~h}$. Then, $30 \mu \mathrm{L}$ of mixed cultures of $T$. pyogenes and luteolin were inoculated into $3 \mathrm{~mL}$ of $\mathrm{MH}(\mathrm{B})$ containing $8 \% \mathrm{FBS}$ and cultured to the logarithmic phase. The changes in the MICs of macrolides against T. pyogenes after luteolin treatment were determined following the broth microdilution method. The same method was used to analyse the effect of reserpine on the susceptibility of T. pyogenes to macrolides. Staphylococcus aureus ATCC29213 was included as a quality control strain in all antimicrobial susceptibility assays, and MIC data were accepted only if the MIC of the control strain was within the required reference ranges. The determinations were performed in triplicate.

\section{Analysis of the expression of $m s r A$ using quantitative real-time PCR}

The effects of luteolin on the transcription level of the $m s r A$ gene were determined by quantitative real-time PCR (qRT-PCR). T. pyogenes cultured to the logarithmic phase was diluted to $1 \times 10^{5} \mathrm{CFU} / \mathrm{mL}$ and mixed with luteolin (final concentration, 1/2 MIC). The same method was used to treat $T$. pyogenes with reserpine at a final concentration of $1 / 2$ MIC. The same final concentration of DMSO ( $\mathrm{v} / \mathrm{v}, 0.01 \%)$ was added as a solvent control. After the bacterial suspension was incubated at $37{ }^{\circ} \mathrm{C}$ and $180 \mathrm{rpm}$ for $36 \mathrm{~h}, 50 \mathrm{~mL}$ of culture was harvested to collect bacterial cells by centrifugation for 2 min at $12000 \mathrm{rpm}$ and $4{ }^{\circ} \mathrm{C}$. Total RNA of T. pyogenes was extracted using TRIzol Reagent (Ambion, Carlsbad, USA), and cDNA was synthesized using a PrimeScript ${ }^{\mathrm{TM}}$ RT Reagent Kit with gDNA Eraser (TaKaRa, Dalian, China).

The transcription level of the $m s r A$ gene was measured using a TB Green ${ }^{\circledR}$ Premix $E x$ Taq $^{\mathrm{TM}}$ II Kit (TaKaRa, Dalian, China) on an Applied Biosystems ${ }^{\circledR}$ QuantStudio ${ }^{\circledR}$ 3 Real-Time PCR System (Thermo Fisher, USA) according to the manufacturer's instructions. The $16 \mathrm{~S} r R N A$ of T. pyogenes was used as a reference gene for comparison in qRT-PCR. The primer sequences are shown in Table 1. The qRT-PCR conditions were set as follows: initial denaturation at $95^{\circ} \mathrm{C}$ for $3 \mathrm{~min} ; 40$ cycles of $95^{\circ} \mathrm{C}$ for $10 \mathrm{~s}, 60^{\circ} \mathrm{C}$ for $10 \mathrm{~s}$, and $72{ }^{\circ} \mathrm{C}$ for $30 \mathrm{~s}$; followed by a melting curve at $95^{\circ} \mathrm{C}$ for $15 \mathrm{~s}, 60^{\circ} \mathrm{C}$ for $60 \mathrm{~s}$, and finally $95{ }^{\circ} \mathrm{C}$ for $1 \mathrm{~s}$. The relative expression of the $m s r A$ gene was normalized against that of $16 S$ rRNA and quantified using the $2^{-\Delta \Delta C t}$ method. Three independent experiments were carried out in duplicate.
Table 1 Primer sequences used in qRT-PCR assays

\begin{tabular}{lll}
\hline Gene & Orientation & Sequence $\left(\mathbf{5}^{\prime} \mathbf{-} \mathbf{3}^{\prime} \mathbf{)}\right.$ \\
\hline$m s r A$ & Forward & GGCATACTATCGTCAACTTG \\
& Reverse & ATACTGCTAACGATAATTTCG \\
16S rRNA & Forward & ATGCAACGCGAAGAACCTTACC \\
& Reverse & TTAACCCAACATCTCACGACAC \\
\hline
\end{tabular}

Table 2 Primer sequences used in the expression of the HisMsrA fusion protein

\begin{tabular}{llll}
\hline Gene & Orientation & Sequence $\left(\mathbf{5}^{\prime} \mathbf{-} \mathbf{3}^{\prime}\right)$ & Restriction site \\
\hline msra & Forward & GGATCCATGGAACAA & BamHI \\
& & TATACAATTAAATTTAAC & \\
& & CAAATCA & \\
& Reverse & AAGCTTTTAAGTTATATC & Hind III \\
& & ATGAATAGATTGTCC & \\
& & TGTTAATTCC & \\
& &
\end{tabular}

\section{Preparation of a polyclonal antibody against His-MsrA protein}

The coding sequence of $m s r A$ was amplified from the genomic DNA of strain BM-H06-3. Primers were designed based on the multiple cloning site of the pET$28 \mathrm{a}$ vector. The primers and restriction sites are shown in Table 2. The PCR product of $m s r A$ was ligated with the linearized $\mathrm{pET}-28 \mathrm{a}$ vector to generate the recombinant plasmid pET-28a-msr $A$, which was then transformed into E. coli BL21 (DE3) cells. The bacteria were cultured in LB medium supplemented with $50 \mu \mathrm{g} / \mathrm{mL}$ kanamycin. When the cell density of BL21 (DE3) reached $0.4-0.6$ at $\mathrm{OD}_{600}$ $\mathrm{nm}, 1 \mathrm{mM}$ isopropyl- $\beta$-D-thiogalactoside (IPTG, Sigma, USA) was added to the medium to induce the expression of His-MsrA fusion protein at $16{ }^{\circ} \mathrm{C}$ for $12 \mathrm{~h}$ [28]. The bacterial cells induced by IPTG were harvested, resuspended in PBS ( $\mathrm{pH} 7.4$ ) and lysed by sonication on ice (3 s on and $3 \mathrm{~s}$ off, total of $20 \mathrm{~min}$ ). After sonication, the total proteins existed in the supernatant after centrifugation at $4{ }^{\circ} \mathrm{C}$ and $12000 \mathrm{rpm}$ for $10 \mathrm{~min}$. The His-MsrA protein was purified using a His GraviTrap (GE Healthcare, Sweden) according to the manufacturer's recommendations. The purified protein was identified by Western blotting analysis using an anti-His mouse monoclonal antibody (TransGen Biotech, Beijing, China) and HRP-conjugated goat anti-mouse IgG (TransGen Biotech, Beijing, China) [29].

The purified His-MsrA fusion protein was used to produce a polyclonal antibody. Briefly, adult New Zealand white rabbits were immunized by the subcutaneous route with $400 \mu \mathrm{g}$ of His-MsrA protein mixed with an equal volume of complete Freund's adjuvant (Sigma-Aldrich, 
Table 3 The MIC of luteolin against T. pyogenes $(\mu \mathrm{g} / \mathrm{mL})$

\begin{tabular}{|c|c|c|c|c|c|c|c|c|c|c|}
\hline \multirow[t]{2}{*}{ Drug name } & \multicolumn{10}{|c|}{ Strain number } \\
\hline & HCO3-1 & $\mathrm{HC}-\mathrm{H} 03-3$ & $\mathrm{HC}-\mathrm{H} 02-2$ & BM07-1 & BM-H06-3 & BM-H11-1 & BM-H01-1 & RY04-2 & $\mathrm{HC}-\mathrm{H} 10$ & RY14-3 \\
\hline Luteolin & 78 & 78 & 78 & 78 & 156 & 78 & 78 & 78 & 78 & 78 \\
\hline Reserpine & 5 & 5 & 5 & 5 & 20 & 20 & 20 & 20 & 20 & 40 \\
\hline
\end{tabular}

Shanghai, China) at the first injection. Two weeks later, the rabbits were given three booster injections of $400 \mu \mathrm{g}$ of fusion protein with incomplete Freund's adjuvant (Sigma-Aldrich, Shanghai, China) every week. One week later, the rabbits were bled to collect the antiserum [30]. The purified fusion protein was used as a coating antigen to detect the titres of the anti-His-MsrA polyclonal antibody by indirect enzyme-linked immunosorbent analysis (ELISA).

\section{Extraction of T. pyogenes total proteins and Western blotting analysis of MsrA}

The treatment method of $T$. pyogenes samples was the aforementioned method in "Analysis of the expression of $m s r A$ using quantitative real-time PCR". After the bacterial suspension was incubated on a shaker at $37{ }^{\circ} \mathrm{C}$ and $180 \mathrm{rpm}$ for $36 \mathrm{~h}, 100 \mathrm{~mL}$ of the bacterial suspension was centrifuged at $12000 \mathrm{rpm}$ and $4{ }^{\circ} \mathrm{C}$ for $2 \mathrm{~min}$. The bacterial cells were fully mixed with $2 \mathrm{~mL}$ of bacterial protein extraction reagent (CWBIO, Beijing, China) and $20 \mu \mathrm{L}$ of protease inhibitor cocktail (CWBIO, Beijing, China). The mixture was sonicated on ice (3s on and $3 \mathrm{~s}$ off, total of $20 \mathrm{~min}$ ) and centrifuged at $12000 \mathrm{rpm}$ for $10 \mathrm{~min}$ at $4{ }^{\circ} \mathrm{C}$ to acquire the total cell proteins. The protein concentration was measured using a BCA protein assay kit (Thermo Fisher, USA).

The protein expression level of MsrA after luteolin treatment was determined by Western blotting. Briefly, the total proteins from $T$. pyogenes were run on a $12 \%$ SDS-PAGE gel and then transferred onto PVDF membranes (Millipore, Germany). After blocking with 5\% skim milk in TBST buffer at $4{ }^{\circ} \mathrm{C}$ for $12 \mathrm{~h}$, membranes were incubated with the anti-His-MsrA polyclonal antibody at a dilution of 1:5000 for $2 \mathrm{~h}$ at $37^{\circ} \mathrm{C}$. Then, membranes were washed three times with TBST buffer for $10 \mathrm{~min}$ each time and incubated with HRP-conjugated goat anti-rabbit IgG (1:10 000) (Sangon, Shanghai, China), which was used as the secondary antibody, at $37{ }^{\circ} \mathrm{C}$ for $2 \mathrm{~h}$. An anti-GAPDH mouse monoclonal antibody (Sangon, Shanghai, China) was used to detect the expression of the reference protein, and HRP-conjugated goat anti-mouse IgG (Sangon, Shanghai, China) was used as the secondary antibody [31]. Finally, after being washed three times with TBST buffer as above, the membranes were visualized using an EasySee ${ }^{\circledR}$ Western Blot Kit (TransGen Biotech, Beijing, China) and an Azure c300 imaging system (Azure, USA).

\section{Affinity test of luteolin to MsrA}

To explore the interaction between luteolin and the MsrA protein, the affinity of luteolin to the MsrA protein was tested using surface plasmon resonance (SPR) with a Biacore T200 system (GE Healthcare, Sweden). Briefly, the fusion protein His-MsrA was captured on an NTA sensor chip (GE Healthcare, Sweden) by chelation of $\mathrm{Ni}^{2+}$ through NTA on the surface and histidine residues in the ligand tag. Luteolin was diluted with PBS-P (GE Healthcare, Sweden) to a series of concentrations $(12.5,25,50$, $100,200$, and $400 \mu \mathrm{M})$. The luteolin solution was flowed at a rate of $30 \mu \mathrm{L} / \mathrm{min}$ for $180 \mathrm{~s}$ to allow for association, followed by $300 \mathrm{~s}$ for dissociation over captured protein in PBS-P running buffer [32]. The binding ability of luteolin to the His-MsrA protein was evaluated by the equilibrium dissociation constant (KD) using Biacore T200 Evaluation Software 3.0.

\section{Structure prediction of MsrA and docking analysis}

Homology modelling was used to predict the tertiary structure of the MsrA protein. The protein sequence was submitted to the online protein structure homologymodelling website [33], and then homologous proteins with high sequence homology were searched in the database for each amino acid sequence. Using these proteins with known crystal structures as templates, a threedimensional (3D) structure model of the target protein was constructed. The protein with the highest homology was selected to construct the $3 \mathrm{D}$ structure of the target protein, which was saved in PDB file format for subsequent molecular docking. For ligand preparation, the structure of luteolin was drawn using ChemDraw Ultra 7.0, energy-minimized in Chem3D Ultra 7.0 and saved as a PDB file. AutoDock is a suite of tools used to predict interactions between small molecules (ligands) and proteins of known 3D structure based on the properties (polar atoms and bond rotations) of the ligand and the 

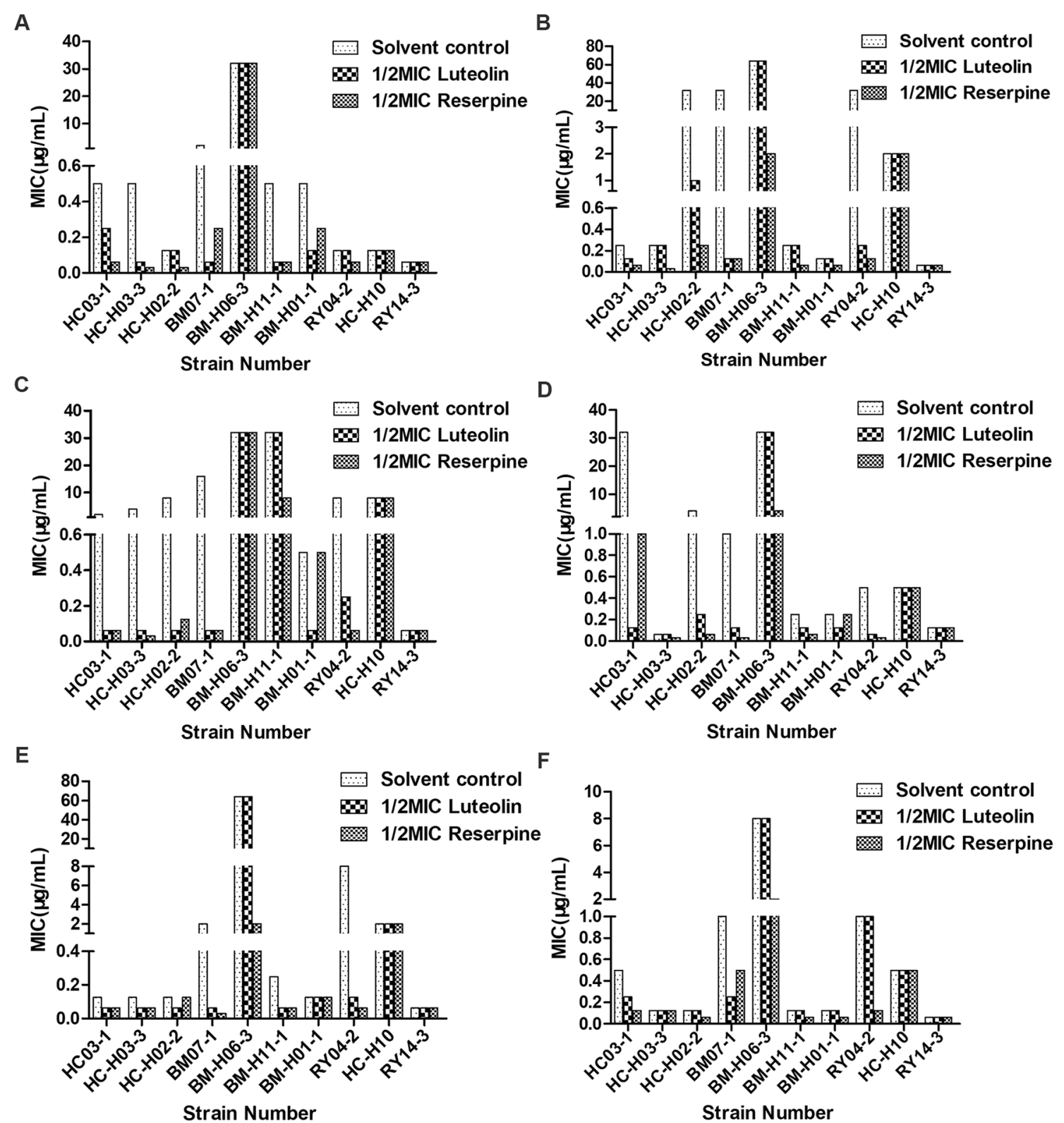

Figure 1 The changes in the MICs of six macrolides against T. pyogenes after luteolin treatment. A Erythromycin, B roxithromycin, C acetylspiramycin, $\mathbf{D}$ tylosin, E azithromycin, $\mathbf{F}$ tilmicosin.

binding site of the protein [34]. AutoDock 4.2 was used for the molecular docking of luteolin and MsrA protein.

\section{Statistical analysis}

The results of qRT-PCR and Western blotting are expressed as the mean \pm standard deviation (SD) of three independent experiments. Statistical analysis was performed by GraphPad Prism (scientific 2D graphing and statistics software, version 6.0, California Corporation) and one-way analysis of variance (ANOVA) in
SPSS Statistics (IBM Company, version 17.0, SPSS Inc., New York, USA). Statistical significance was defined as $* / \# P<0.05$ and $* * \# \# P<0.01$.

\section{Results}

\section{Luteolin increases the susceptibility of T. pyogenes} to macrolides

The minimum inhibitory concentrations (MICs) of luteolin and reserpine against $T$. pyogenes are presented in Table 3. The MICs of luteolin against each isolate were 


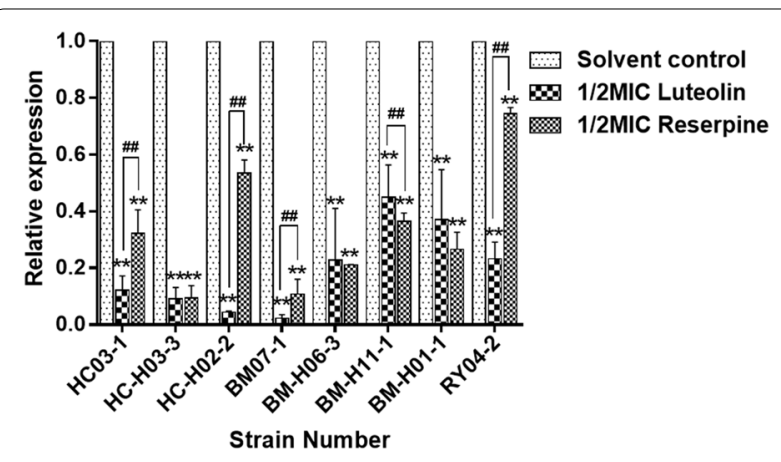

Figure 2 The relative expression level of the $m s r A$ gene after luteolin treatment. Data were presented as means \pm SDs $\left({ }^{*}\right.$ compared with solvent control, \#compared with reserpine, ${ }^{*} / \#$ $P<0.05$, **/\#\# $P<0.01)$

all $78 \mu \mathrm{g} / \mathrm{mL}$ except BM-H06-3 (156 $\mu \mathrm{g} / \mathrm{mL})$, regardless of whether these strains carried efflux pumps. The MICs of reserpine, a test control, against $T$. pyogenes strains ranged from 5 to $40 \mu \mathrm{g} / \mathrm{mL}$.

It was found that $1 / 2 \mathrm{MIC}$ luteolin treatment for $36 \mathrm{~h}$ could best increase the susceptibility of $T$. pyogenes to macrolides. After treatment with luteolin at $1 / 2 \mathrm{MIC}$, the MICs of macrolides against $T$. pyogenes decreased by 1-256-fold, and a similar situation occurred in isolates treated with reserpine (shown in Figure 1). Among eight msrA-positive T. pyogenes isolates (HC03-1, HC-H03-3, HC-H02-2, BM-07-1, BM-H06-3, BM-H11-1, BM-H01-1 and RY04-2), six isolates showed increased susceptibility to acetylspiramycin, tylosin and azithromycin (Figures 1C-E), five isolates showed increased susceptibility to erythromycin (Figure 1A), four isolates showed increased susceptibility to roxithromycin (Figure 1B), and only two isolates showed increased susceptibility to tilmicosin (Figure 1F). Conversely, after luteolin treatment, the MICs of six macrolides against $m s r A$-negative T. pyogenes isolates (HC-H10 and RY14-3) showed no changes, which indicated that luteolin may influence the MsrA efflux pump activity in T. pyogenes, leading to a decrease in macrolide resistance.

\section{Effects of luteolin on the transcription level of the $m s r A$ gene}

qRT-PCR was used to investigate the effects of luteolin on the transcription level of the $m s r A$ gene. After luteolin and reserpine treatment, the relative mRNA expression of the $m s r A$ gene showed different degrees of reduction in all T. pyogenes strains that produced the MsrA pump (Figure 2). Compared with the solvent control group, the expression of the $m s r A$ gene decreased by $55.0-97.7 \%$ in the luteolin treatment group and $25.5-90.6 \%$ in the reserpine treatment group. The expression of the $m s r A$ gene in BM07-1 was the lowest after luteolin treatment. In the reserpine treatment group, the relative expression of the $m s r A$ gene in $\mathrm{HC}-\mathrm{H} 03-3$ was the lowest.

\section{Effects of luteolin on the protein expression level of MsrA}

To investigate the effect of luteolin on the protein expression level of MsrA, polyclonal antibodies against HisMsrA were prepared by immunizing New Zealand white rabbits. The purification and identification results of the His-MsrA fusion protein are shown in Figures 3A and $\mathrm{B}$, which indicated that the His-MsrA protein was successfully purified. The ELISA results showed that the titre of the anti-His-MsrA polyclonal antibody reached 1:256 000, which showed that the rabbit antiserum was expected to successfully recognize the MsrA protein of $T$. pyogenes (Figure $3 \mathrm{C}$ ). After obtaining the anti-His-MsrA polyclonal antibody, the effects of luteolin on the protein expression of MsrA in T. pyogenes were analysed by Western blotting assays. Western blotting assays of MsrA

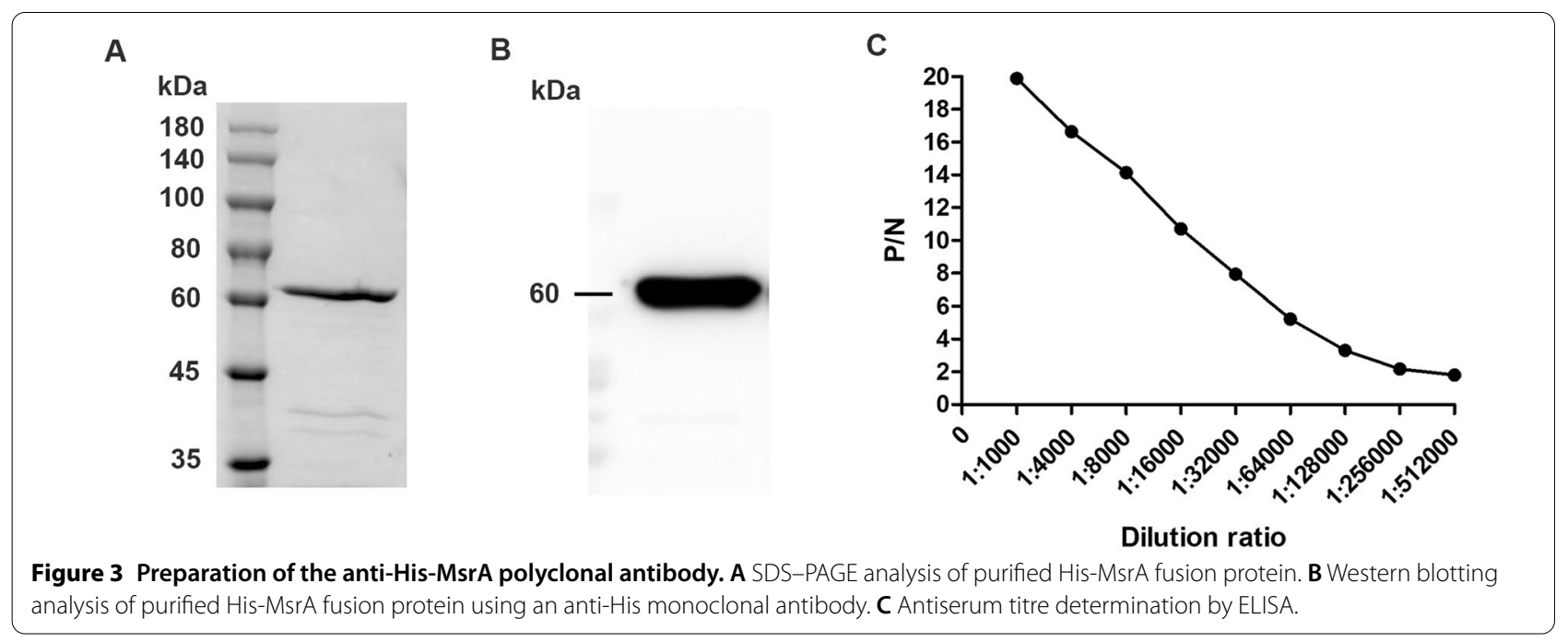


A

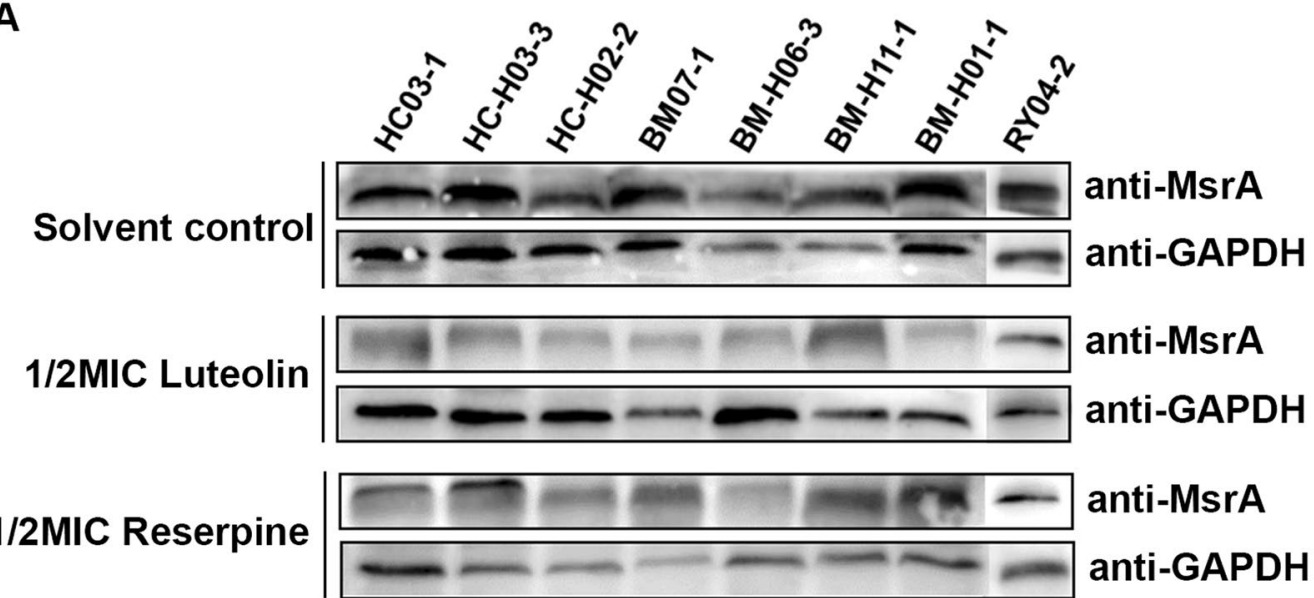

B

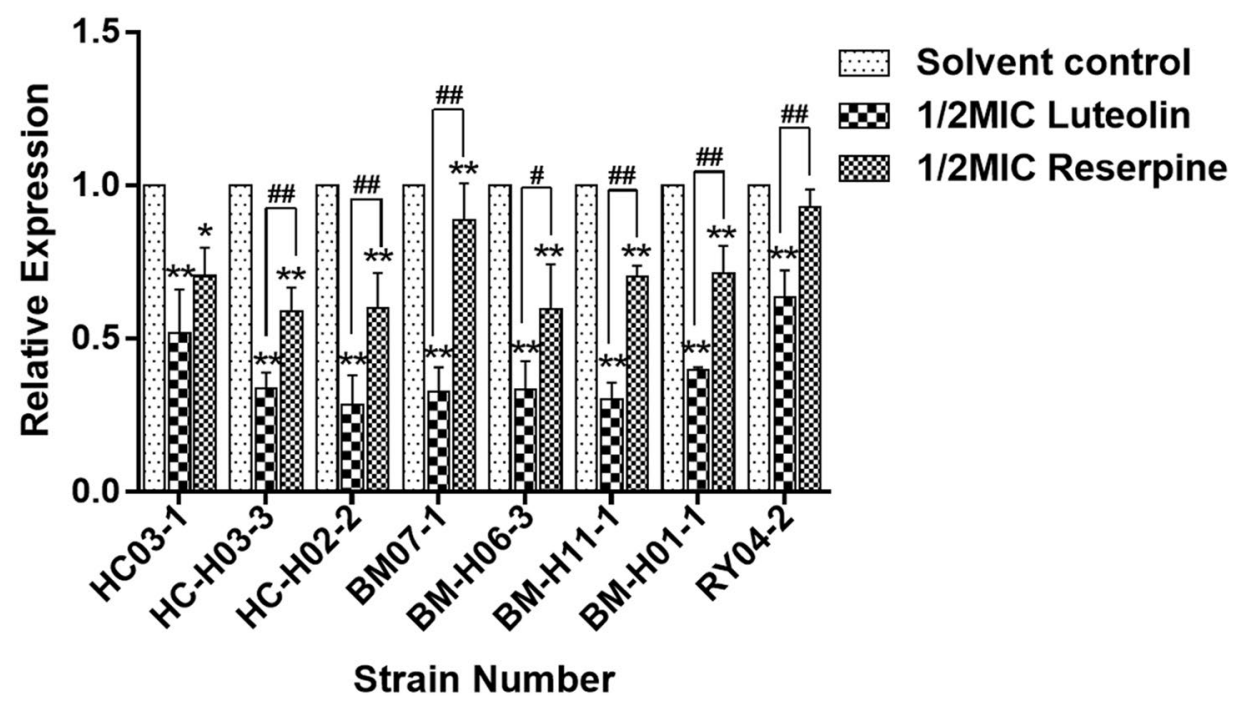

Figure 4 The effect of luteolin on the expression level of the MsrA protein. A Western blotting results of the MsrA protein in T. pyogenes after luteolin treatment. The experiment was repeated separately three times, and one representative blot is shown. $\mathbf{B}$ The relative expression level of the MsrA protein after luteolin treatment. Data were presented as means \pm SDs $\left({ }^{*}\right.$ compared with solvent control, \#compared with reserpine, ${ }^{*} / \# P<0.05$, **\#\#P<0.01).

protein were repeated three times, and one representative blot is shown (Figure 4A). As shown in Figures 4B, among all $m s r A$-positive $T$. pyogenes isolates, the relative expression of MsrA decreased by $36.5-71.5 \%$ after 1/2 MIC luteolin treatment for $36 \mathrm{~h}$. Similarly, reserpine also significantly reduced the protein expression level of MsrA (decreased by 6.9-41.2\%). However, luteolin caused a lower expression level of MsrA than reserpine in all $m s r A$-positive $T$. pyogenes isolates.

The affinity of luteolin and MsrA protein

To verify whether luteolin could interact with MsrA, the affinity was assessed using surface plasmon resonance (SPR) with a Biacore T200 system. The sensor diagram and fitting curve are shown in Figure 5. As shown in Figure 5A, luteolin and MsrA protein combined at 0-180 $\mathrm{s}$ and dissociated at 180-480 s. The KD value for the interaction between luteolin and MsrA protein was $6.462 \times 10^{-5} \mathrm{M}$ (Figure $5 \mathrm{~B}$ ), representing a reliable affinity between luteolin and the MsrA protein. The results of the affinity assay demonstrated that luteolin can bind with MsrA, which was further verified by molecular docking.

\section{Molecular modelling of the MsrA protein and docking analysis}

The AutoDock program was used to predict the interaction site of luteolin with the MsrA protein. First, the 3D structure of the MsrA protein was generated after the 


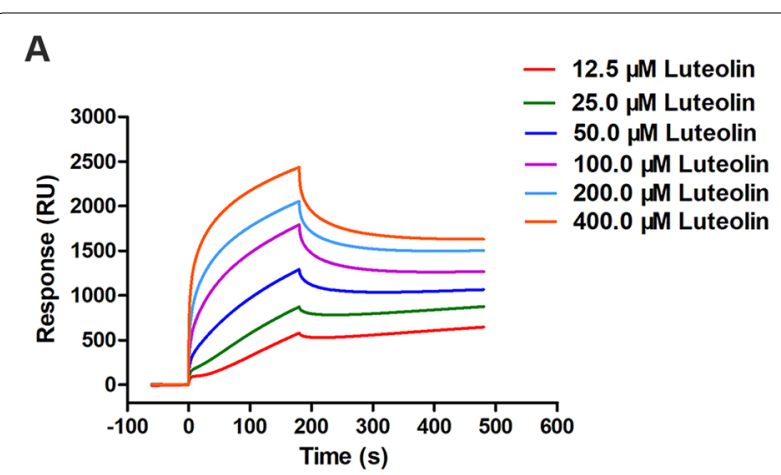

B

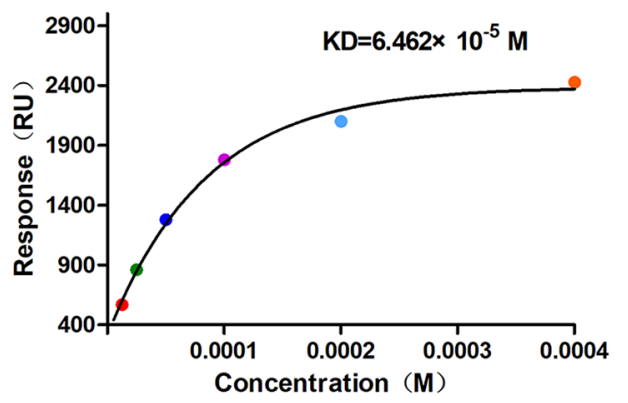

Figure 5 Detection of the interaction between luteolin and the MsrA protein by SPR. A Affinity sensing diagram for a series of concentrations of luteolin with MsrA protein. B Affinity fitting curve of luteolin with the MsrA protein.

amino acid sequence was submitted to the online protein structure prediction website. The predicted model was obtained based on the protein sequence of MsrA as well as on amino acid sequence alignment and structure comparison. The predicted model of MsrA (SMTL ID: 6ha8.1) is shown in Figure 6A, and the three-dimensional structure of MsrA was exported in PDB file format. The 3D docking results of luteolin with MsrA showed that luteolin lies in the hydrophobic pocket of the MsrA active site (Figure 6B) and interacts with Gly39, Asn40, Gly41, Thr42, Gly43, Lys44, Gln73, His157 and Phe439 (Figure $6 \mathrm{C})$. Among these amino acid residues, most of them (Gly39, Asn40, Gly41, Thr42, Gly43 and Lys44) belong to ATP-binding and ATPase active regions. Therefore, it is predicted that luteolin may inhibit the efflux of drugs by preventing the MsrA efflux pump from obtaining energy. The two-dimensional (2D) docking results showed that luteolin interacted with MsrA mainly through conventional hydrogen bonds and carbon hydrogen bonds (Figure 6C).

\section{Discussion}

Identifying compounds that inhibit efflux pumps is a promising method to combat resistant bacteria. Many studies have reported that flavonoids could reverse the resistance of bacteria. For example, silybin could restore the susceptibility of methicillin-resistant Staphylococcus aureus (MRSA) to ciprofloxacin by inhibiting the expression of efflux genes and proteins [35]. Belofsky reported that a new flavonoid could potentiate the activity of antimicrobials through inhibition of NorA multidrug resistance (MDR) pumps [36]. Additionally, hydnocarpins and their derivatives showed efficient inhibitory activity on the NorA efflux pump of Staphylococcus aureus and its increased susceptibility to enrofloxacin [37].

Previous studies have shown that luteolin exhibits multiple pharmacological effects, such as antibacterial, anti-inflammatory, antioxidant, and antitumour effects [23, 24], but the effect of luteolin on efflux pumps is still unclear. In this study, the MICs of six macrolides against T. pyogenes after luteolin treatment were analysed. We found that treatment with luteolin at a $1 / 2 \mathrm{MIC}$ concentration for $36 \mathrm{~h}$ could maximize the susceptibility of $m s r A$-positive $T$. pyogenes isolates to macrolides. However, the susceptibility of $m s r A$-negative $T$. pyogenes isolates to macrolides showed no changes after luteolin treatment, which indicated that luteolin increased the susceptibility of $T$. pyogenes by acting on MsrA. Reserpine has been widely studied as a general inhibitor of efflux pumps. Although this molecule can inhibit the $\mathrm{ABC}$ transporters involved in the extrusion of antibiotics, the concentrations necessary to block bacterial efflux are neurotoxic [38]. In this study, luteolin, known to have many pharmacological activities and almost no toxicity [39], had the same effect as reserpine in reversing the resistance of T. pyogenes.

We found that the susceptibility of $m s r A$-positive $T$. pyogenes varied after luteolin treatment. It is worth noting that the MICs of macrolides did not change after luteolin treatment for strain BM-H06-3. Our previous study showed that there were two site mutations (A753T and G754T) in the 23S rRNA II region of strain BM-H06-3, which also mediated high-level resistance to macrolides. This may be the reason why luteolin failed to reverse the resistance of strain BM-H06-3. However, after reserpine treatment, the MICs of the four macrolides against strain BM-H06-3 decreased, which indicated that the action mechanisms of luteolin and reserpine as efflux pump inhibitors were different.

Efflux pumps can be inhibited by EPIs in different ways: (i) downregulating the expression of the efflux pump gene, (ii) interfering with the assembly of efflux pump proteins, (iii) blocking the efflux pump to avoid substrate binding to the active site, and (iv) blocking the energy supply so that the efflux pump loses its energy source [40]. It has been reported that MRSA treated with silybin for $16 \mathrm{~h}$ showed a $36 \%$ and $49 \%$ reduction in the expression of the nor $A$ and $q a c A / B$ genes and became sensitive to ciprofloxacin 


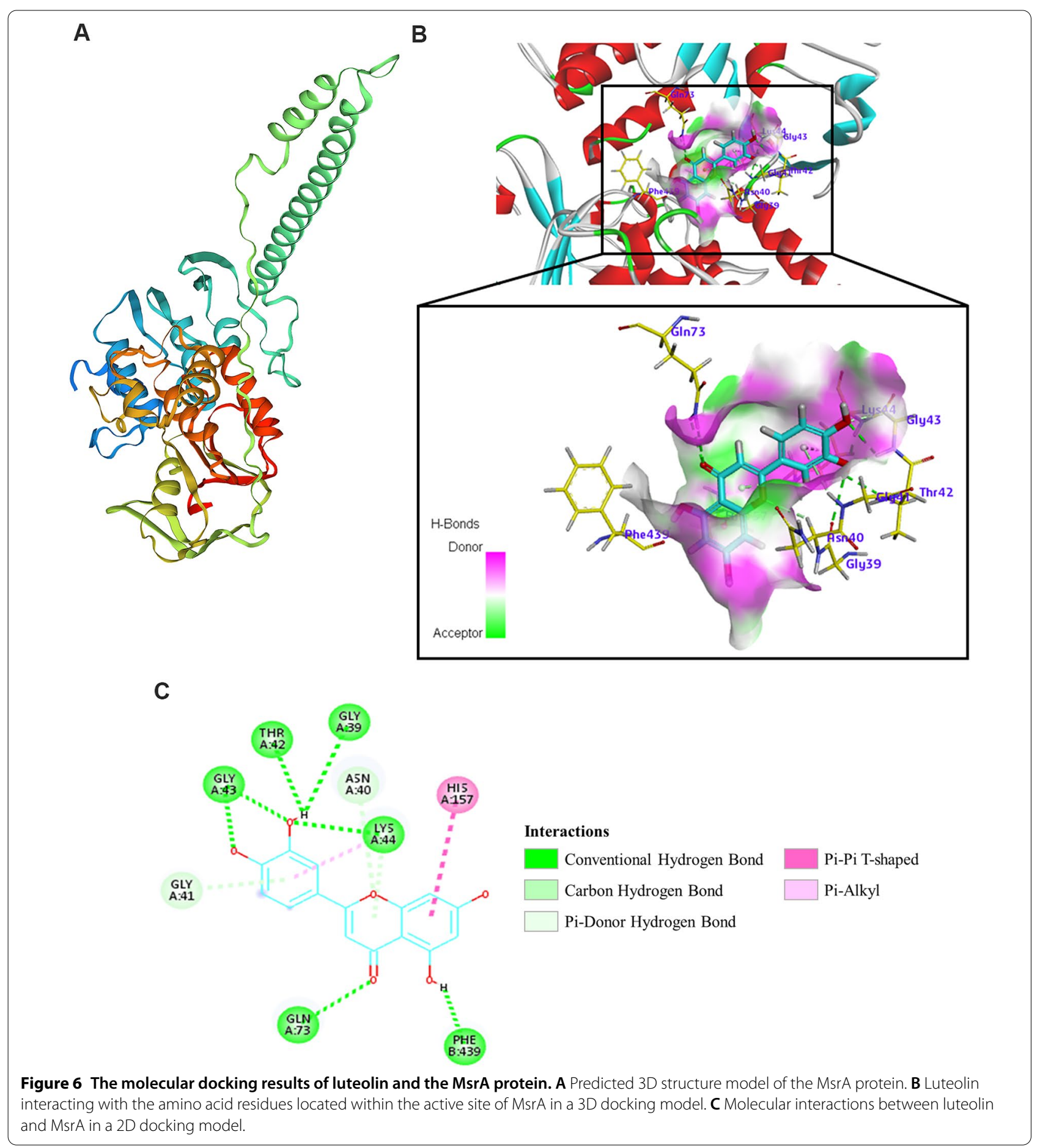

[35]. Ketoconazole could increase the susceptibility of Staphylococcus aureus to fluoroquinolones, and the inhibition of the expression of norA, which encodes an efflux pump, may contribute to this phenomenon [15]. In this study, the qRT-PCR results showed that luteolin could significantly inhibit the expression of the $m s r A$ gene (Figure 2). Interestingly, we found that in some strains (HC03-1, HC-H03-3, HC-H02-2, BM07-1, and RY04-2), the inhibitory effect of luteolin on $m s r A$ gene expression was stronger than that of reserpine, while in some strains (BM-H06-3, BM-H11-1, and BM-H01-1), the opposite trend was observed. This distinction may 
be due to the differences in their mechanisms of action on the inhibition of $m s r A$ gene transcription.

We further verified whether luteolin affected the expression of the MsrA protein. As shown in Figure 4, luteolin significantly downregulated the expression of the MsrA protein in T. pyogenes. Although the effects of luteolin and reserpine on $m s r A$ gene expression were irregular, the expression level of the MsrA protein in all $m s r A$-positive isolates after luteolin treatment was lower than that after reserpine treatment. These results indicate that luteolin may also act on the posttranscriptional processing of the $m s r A$ gene, resulting in lower expression of MsrA protein in comparison with that in cells treated with reserpine.

Some efflux pump inhibitors can bind efflux pumps, resulting in a reduced ability of the efflux pumps to interact with their substrates [41]. Crystallization studies have shown that verapamil, a typical EPI, could bind to the active site of the MATE efflux pumps, similar to the substrates of the pumps [42]. Quercetin, a flavonoid compound, could stably bind to the Mmr pump in Mycobacterium tuberculosis and the EmrE pump in Escherichia coli [43]. In this study, the results of the affinity test revealed that luteolin had a reliable binding ability with MsrA (Figure 5). We further used molecular docking technology to analyse the binding site of luteolin with MsrA. The results showed that luteolin lies in the active pocket of MsrA and interacts with amino acid residues mainly by hydrogen bonds (Figure 6). Importantly, we found that most of the amino acid residues (Gly39, Asn40, Gly41, Thr42, Gly43, and Lys44) interacting with luteolin were located in the ATP-binding and ATPase active regions of MsrA. This binding probably caused MsrA, an ATPdependent efflux pump, to lose its ability to discharge substrates due to a lack of energy supply. Tariquidar is a third-generation P-glycoprotein inhibitor that binds to the ATP-binding site of P-glycoprotein and inhibits the efflux pump by inhibiting ATPase activity [44]. Luteolin may share a similar mechanism with tariquidar.

In conclusion, this study indicated that luteolin is a potential efflux pump inhibitor that can increase the susceptibility of $T$. pyogenes to macrolides by targeting the MsrA efflux pump. The results of this research showed that luteolin inhibits the activity of the MsrA efflux pump of T. pyogenes mainly through the following mechanisms: (i) inhibiting the expression of the $m s r A$ gene and MsrA protein and (ii) interacting with ATP-binding and ATPase activity regions of the MsrA efflux pump and blocking the energy acquisition of the MsrA efflux pump. Therefore, luteolin may be a potential EPI for use in combating infections caused by antimicrobial-resistant bacteria.

\section{Acknowledgements}

We gratefully acknowledge Shengli Niu for his technical assistance in the molecular docking study.

\section{Authors' contributions}

Funding acquisition: ML. Experiment conception and design: ML and YG. Experiment performance: YG, CH, HS and ZZ. Software: YG, RW and MC. Data analysis: YG, DZ and LZ. Writing:YG. Review and editing: ML and DZ. Supervision: ML. All authors read and approved the final manuscript.

\section{Funding}

This research was funded by the National Natural Science Foundation of China, Grant Numbers 31972736 and 31572564.

\section{Availability of data and materials}

The datasets used and/or analysed during the current study are included in this article or are available from the corresponding author on reasonable request.

\section{Declarations}

\section{Ethics approval and consent to participate}

The animal experiments were carried out following the recommendations of the laboratory animal administration rules of the State Scientific and Technological Commission. The protocol was approved by the Ethics Committee of Shenyang Agricultural University (SYXK(Liao)2011-0001, Shenyang, China).

\section{Competing interests}

The authors declare that they have no competing interests.

Received: 27 September 2021 Accepted: 29 November 2021

Published online: 10 January 2022

\section{References}

1. Galán-Relaño Á, Gómez-Gascón L, Luque I, Barrero-Domínguez B, Casamayor A, Cardoso-Tose F, Vela Al, Fernández-Garayzábal JF, Tarradas C (2019) Antimicrobial susceptibility and genetic characterization of Trueperella pyogenes isolates from pigs reared under intensive and extensive farming practices. Vet Microbiol 232:89-95

2. Dong WL, Odah KA, Liu L, Xu QJ, Gao YH, Kong LC, Ma HX (2020) Multidrug resistance genes are associated with a 42 -kb island TGI 1 carrying a complex class 1 integron in Trueperella pyogenes. J Glob Antimicrob Resist 22:1-4

3. Rzewuska M, Kwiecień E, Chrobak-Chmiel D, Kizerwetter-Świda M, Stefańska I, Gieryńska M (2019) Pathogenicity and virulence of Trueperella pyogenes: a review. Int J Mol Sci 20:2737

4. Ribeiro MG, Risseti RM, Bolaños CA, Caffaro KA, de Morais AC, Lara GH, Zamprogna TO, Paes AC, Listoni FJ, Franco MM (2015) Trueperella pyogenes multispecies infections in domestic animals: a retrospective study of 144 cases (2002 to 2012). Vet Q 35:82-87

5. Rzewuska M, Stefańska I, Osińska B, Kizerwetter-Świda M, Chrobak D, Kaba J, Bielecki W (2012) Phenotypic characteristics and virulence genotypes of Trueperella (Arcanobacterium) pyogenes strains isolated from European bison (Bison bonasus). Vet Microbiol 160:69-76

6. Meili Z (2020) Trueperella pyogenes pharyngitis in an immunocompetent 40-year-old man. BMJ Case Rep 13:e236129

7. Rzewuska M, Czopowicz M, Gawryś M, Markowska-Daniel I, Bielecki W (2016) Relationships between antimicrobial resistance, distribution of virulence factor genes and the origin of Trueperella pyogenes isolated from domestic animals and European bison (Bison bonasus). Microb Pathog 96:35-41

8. de Boer M, Heuer C, Hussein H, McDougall S (2015) Minimum inhibitory concentrations of selected antimicrobials against Escherichia coli and Trueperella pyogenes of bovine uterine origin. J Dairy Sci 98:4427-4438

9. Pohl A, Lübke-Becker A, Heuwieser W (2018) Minimum inhibitory concentrations of frequently used antibiotics against Escherichia coli and 
Trueperella pyogenes isolated from uteri of postpartum dairy cows. J Dairy Sci 101:1355-1364

10. Zhang D, Zhao J, Wang Q, Liu Y, Tian C, Zhao Y, Yu L, Liu M (2017) Trueperella pyogenes isolated from dairy cows with endometritis in Inner Mongolia, China: tetracycline susceptibility and tetracycline-resistance gene distribution. Microb Pathog 105:51-56

11. Galán-Relaño Á, Gómez-Gascón L, Barrero-Domínguez B, Luque I, JuradoMartos F, Vela Al, Sanz-Tejero C, Tarradas C (2020) Antimicrobial susceptibility of Trueperella pyogenes isolated from food-producing ruminants. Vet Microbiol 242:108593

12. Blair JMA, Webber MA, Baylay AJ, Ogbolu DO, Piddock LJV (2015) Molecular mechanisms of antibiotic resistance. Nat Rev Microbiol 13:42-51

13. Pontes DS, de Araujo RSA, Dantas N, Scotti L, Scotti MT, de Moura RO, Mendonca-Junior FJB (2018) Genetic mechanisms of antibiotic resistance and the role of antibiotic adjuvants. Curr Top Med Chem 2018:42-74

14. Witek K, Latacz G, Kaczor A, Czekajewska J, Żesławska E, Chudzik A, Karczewska E, Nitek W, Kieć-Kononowicz K, Handzlik J (2020) Phenylpiperazine 5,5-dimethylhydantoin derivatives as first synthetic inhibitors of Msr(A) efflux pump in Staphylococcus epidermidis. Molecules 25:3788

15. Abd El-Baky RM, Sandle T, John J, Abuo-Rahma GA, Hetta HF (2019) A novel mechanism of action of ketoconazole: inhibition of the NorA efflux pump system and biofilm formation in multidrug-resistant Staphylococcus aureus. Infect Drug Resist 12:1703-1718

16. Song L, WuX (2016) Development of efflux pump inhibitors in antituberculosis therapy. Int J Antimicrob Agents 47:421-429

17. Opperman TJ, Nguyen ST (2015) Recent advances toward a molecular mechanism of efflux pump inhibition. Front Microbiol 6:421

18. Laws M, Jin P, Rahman KM (2021) Efflux pumps in Mycobacterium tuberculosis and their inhibition to tackle antimicrobial resistance. Trends Microbiol. https://doi.org/10.1016/j.tim.2021.05.001

19. Gupta S, Tyagi S, Bishai WR (2015) Verapamil increases the bactericidal activity of bedaquiline against Mycobacterium tuberculosis in a mouse model. Antimicrob Agents Chemother 59:673-676

20. Pasca MR, Guglierame P, De Rossi E, Zara F, Riccardi G (2005) mmpL7 gene of Mycobacterium tuberculosis is responsible for isoniazid efflux in Mycobacterium smegmatis. Antimicrob Agents Chemother 49:4775-4777

21. Farhat N, Ali A, Bonomo RA, Khan AU (2020) Efflux pumps as interventions to control infection caused by drug-resistance bacteria. Drug Discov Today 25:2307-2316

22. Solnier J, Martin L, Bhakta S, Bucar F (2020) Flavonoids as novel efflux pump inhibitors and antimicrobials against both environmental and pathogenic intracellular mycobacterial species. Molecules 25:734

23. Qian W, Fu Y, Liu M, Zhang J, Wang W, Li J, Zeng Q, Wang T, Li Y (2021) Mechanisms of action of luteolin against single- and dual-species of Escherichia coli and Enterobacter cloacae and its antibiofilm activities. Appl Biochem Biotechnol 193:1397-1414

24. Shi ML, Chen YF, Wu WQ, Lai Y, Jin Q, Qiu WL, Yu DL, Li YZ, Liao HF (2021) Luteolin inhibits the proliferation, adhesion, migration and invasion of choroidal melanoma cells in vitro. Exp Eye Res 210:108643

25. Zhang D, Gao X, Song X, Zhou W, Hong W, Tian C, Liu Y, Liu M (2019) Luteolin showed a resistance elimination effect on gentamicin by decreasing MATE mRNA expression in Trueperella pyogenes. Microb Drug Resist 25:619-626

26. Choudhuri BS, Bhakta S, Barik R, Basu J, Kundu M, Chakrabarti P (2002) Overexpression and functional characterization of an ABC (ATP-binding cassette) transporter encoded by the genes drrA and drrB of Mycobacterium tuberculosis. Biochem J 367:279-285

27. CLSI (2017) VET06 Methods for Antimicrobial Susceptibility Testing of Infrequently Isolated or Fastidious Bacteria Isolated From Animals, $1^{\text {st }}$ Edition. Clinical and Laboratory Standards Institute, Wayne.

28. Chai H, Wu S, Deng J, Feng L, Yang X, Ran Y, Li H (2019) Preparation and identification of polyclonal antibody against human cytomegalovirus encoding protein UL23. Protein Expr Purif 161:78-83

29. Liu ZD, Xing WJ, Wang LQ, Lv LX (2010) Prokaryotic expression, ascitic polyclonal antibody preparation and identification of cashmere goat Izumo1. Agr Sci China 9:605-613

30. Ni H, Fan W, Li C, Wu Q, Hou H, Hu D, Zheng F, Zhu X, Wang C, Cao X, Shao ZQ, Pan X (2018) Streptococcus suis DivIVA protein is a substrate of Ser/Thr Kinase STK and involved in cell division regulation. Front Cell Infect Microbiol 8:85
31. Yang L, Zhang Y, Wang H, Ma B, Xu L, Wang J, Zhang W (2017) Identification of B-cell linear epitopes in domains 1-3 of pyolysin of Trueperella pyogenes using polyclonal antibodies. Vet Microbiol 210:24-31

32. Wang X, Gou L, Gao Y, Huang Y, Kuai R, LiY, Wang Y, Chen Y, Li J, Cheng C, Feng Z, Wu X, Yao R (2020) RalA exerts an inhibitory effect on IL-1//L-18 secretion by blocking NLRP3 inflammasome activation in levornidazole-treated human THP-1 macrophages. Int Immunopharmacol 88:106898

33. The fully automated protein structure homology-modelling server. https:// swissmodel.expasy.org/interactive

34. Claudio-Campos K, Moneró-Paredes M, Hernández E, Renta J, Duconge J (2019) Low-frequency variants at the CYP2C9 locus among Puerto Rican patients on warfarin: in silico predictions of functionality and conservation. Pharmacogenomics 20:891-902

35. Wang D, Xie K, Zou D, Meng M, Xie M (2018) Inhibitory effects of silybin on the efflux pump of methicillin-resistant Staphylococcus aureus. Mol Med Rep 18:827-833

36. Belofsky G, Percivill D, Lewis K, Tegos GP, Ekart J (2004) Phenolic metabolites of Dalea versicolor that enhance antibiotic activity against model pathogenic bacteria. J Nat Prod 67:481-484

37. Chambers CS, Viktorová J, Řehořová K, Biedermann D, Turková L, Macek T, Křen V, Valentová K (2020) Defying multidrug resistance! Modulation of related transporters by flavonoids and flavonolignans. J Agric Food Chem 68:71763-71779

38. Mahamoud A, Chevalier J, Alibert-Franco S, Kern WV, Pagès JM (2007) Antibiotic efflux pumps in Gram-negative bacteria: the inhibitor response strategy. J Antimicrob Chemother 59:1223-1229

39. Cook MT, Mafuvadze B, Besch-Williford C, Ellersieck MR, Goyette S, Hyder SM (2016) Luteolin suppresses development of medroxyprogesterone acetateaccelerated 7,12-dimethylbenz(a)anthracene-induced mammary tumors in Sprague-Dawley rats. Oncol Rep 35:825-832

40. Sharma A, Gupta VK, Pathania R (2019) Efflux pump inhibitors for bacterial pathogens: from bench to bedside. Indian J Med Res 149:129-145

41. Seukep AJ, Kuete V, Nahar L, Sarker SD, Guo M (2020) Plant-derived secondary metabolites as the main source of efflux pump inhibitors and methods for identification. J Pharm Anal 10:277-290

42. Radchenko M, Symersky J, Nie R, Lu M (2015) Structural basis for the blockade of MATE multidrug efflux pumps. Nat Commun 6:7995

43. Suriyanarayanan B, Sarojini Santhosh R (2015) Docking analysis insights quercetin can be a non-antibiotic adjuvant by inhibiting Mmr drug efflux pump in Mycobacterium sp. and its homologue EmrE in Escherichia coli. J Biomol Struct Dyn 33:1819-1834

44. Leitner I, Nemeth J, Feurstein T, Abrahim A, Matzneller P, Lagler H, Erker T, Langer O, Zeitlinger M (2011) The third-generation P-glycoprotein inhibitor tariquidar may overcome bacterial multidrug resistance by increasing intracellular drug concentration. J Antimicrob Chemother 66:834-839

\section{Publisher's Note}

Springer Nature remains neutral with regard to jurisdictional claims in published maps and institutional affiliations.
Ready to submit your research? Choose BMC and benefit from:
- fast, convenient online submission
- thorough peer review by experienced researchers in your field
- rapid publication on acceptance
- support for research data, including large and complex data types
- gold Open Access which fosters wider collaboration and increased citations
- maximum visibility for your research: over $100 \mathrm{M}$ website views per year

At BMC, research is always in progress.

Learn more biomedcentral.com/submissions 